\title{
Mapping the Catchment Area of Park and Ride Facilities within Urban Environments
}

\author{
Jairo Ortega ${ }^{1, * \mathbb{D}}$, János Tóth ${ }^{1}$ and Tamás Péter ${ }^{2}$ \\ 1 Department of Transport Technology and Economics, Faculty of Transportation Engineering \\ and Vehicle Engineering, Budapest University of Technology and Economics, 1111 Budapest, Hungary; \\ toth.janos@mail.bme.hu \\ 2 Department of Control for Transportation and Vehicle Systems, Faculty of Transportation Engineering \\ and Vehicle Engineering, Budapest University of Technology and Economics, 1111 Budapest, Hungary; \\ peter.tamas@mail.bme.hu \\ * Correspondence: ortega.jairo@mail.bme.hu
}

Received: 1 August 2020; Accepted: 20 August 2020; Published: 21 August 2020

\begin{abstract}
A Park and Ride (P \& R) system is a set of facilities located throughout an urban area that can serve as transfer points for travelers that would like to utilize their private vehicles for one part of their journey and a more sustainable transport mode, such as public transport, for another part of the same journey. The catchment area of the facilities is identified as a fundamental element for planning a P \& R system. It can be assumed to be accurately represented by several geometric shapes, such as a circle or a parabola. In that regard, a method denominated as the parabola method can be used to visualize those geometric shapes on digital maps of an urban environment. It can be implemented as a software program that integrates the variables that represent the elements of the P \& R system as well as the set of equations that are used in a geographic information system (GIS) software. A significant aspect of how the parabola method is applied is its orientation as a shape, which is traditionally configured in respect to the area of major business activity or central business districts (CBDs). In fact, the research presented in this article aims to provide a new approach to the parabola's orientation to study the P \& R system's catchment area by proposing the parabola's orientation according to the primary access that potential users used to reach the facility. A case study that portrays the application of our method is given that is focused on the medium-sized city of Cuenca, Ecuador, where we determine which approach to the parabola's orientation is the most suitable. In conclusion, the second approach proposed in this research reflects in a more realistic form the operation of the catchment area of the P \& R system, considering a better distribution of the coverage area of the P \& R system in the urban environment.
\end{abstract}

Keywords: park and ride; catchment area; GIS environment; accessibility; urban mapping

\section{Introduction}

A Park and Ride (P \& R) system consists of a set of facilities that are strategically allocated along the urban area of a city, and these facilities provide a connection between a private vehicle and public transportation. A more precise definition of $\mathrm{P} \& \mathrm{R}$ is that private vehicle users travel a certain distance and then park the private car to transfer to public transport and finally reach their destination [1-3]. One of the main components for a detailed study of the P \& R system is the catchment area [4-6]. The catchment area is used to delineate the area covered by each facility within the urban areas of a city and as an indicator of whether the location of the facility is appropriate to capture the maximum number of potential users of the P \& R system.

The study and analysis of a catchment area of the $P$ \& R system are carried out through geometrical methods such as the circle, parabola, and hyperbola. The most used is the parabola method; basically, 
this method consists of creating a parabola around a facility that is drawn by the use of a geographical information system (GIS) tool. Therefore, this geometric method involves the use of a GIS tool and the parabola's mathematical formulas $[7,8]$. Using the combination of both methods leads to the development of a software script within a GIS tool by using a programming language that is described as a comprehensive method to define the catchment area of the P \& R in urban mobility. In addition, this method provides an extensive analysis of the parameters that conform to the parabola such as focus, vertices, orientation, and the size of the parabola. The parameters of the parabola and its representation through a GIS tool have been carried out in previous investigations for other types of facilities. A few studies have been carried out on the P \& R system that applies this method $[9,10]$. The common denominator of these few studies is that the parabola is oriented according to the major activity area, such as the central business district (CBD). In order to explain this more clearly, since all the users share the common destination, the parabola would have the same orientation. However, users usually reach the facility through the main road to the same destination, and the main road varies according to the facility location. Therefore, a new approach that is applied in this research is that the parabola's orientation is also based on the main road that allows users to reach the facility.

Our case study is Cuenca city in Ecuador, in which a sustainable mobility plan (SUMP) was developed by the local authorities and stipulates parking policies such as a P \& R system. The facility location has been previously stipulated in a study carried out by Ortega [11]. This study includes seven P \& R facilities near the light rail transit (LRT) stations. Hence, the catchment area study is part of a comprehensive study of the $\mathrm{P} \& \mathrm{R}$ system, and future research needs to determine the parabola's orientation.

The authors have contributed to research on the Park and Ride system in a project called "An integrated study of Park and Ride (P \& R) facilities for sustainable urban mobility". The previous research already published corresponds to the interaction of conventional and autonomous vehicles with the Park and Ride system [12], in addition to the development of an integral model of the P \& R system that allows for the determination of which facility is the most attractive based on the potential demand [13]. Moreover, multi-criteria methods were used to determine a facility location problem and in which experts determined that the criteria of accessibility to public transportation is the most important when implementing a P \& R system [14]. Hence, this research is a significant contribution to the project that is being developed. The authors contributed to this research by conducting a detailed study of the parabola method for the catchment area of the P \& R system. In order to do this research, a software script was developed in a GIS tool to map the catchment area. Thus, two parabola orientation approaches were utilized. The first parabola orientation was based on the traditional concept, which was according to the area of major activity center or the CBDs. In the second approach, the parabola orientation stipulated that potential users reach the facility by the principal road. Finally, a comparative overview of which approach covered the areas of the city more widely helped determine which approach was the most suitable to carry out.

This research is structured in the following sections. Section 2 describes the literature review according to the methods used to define the catchment area of P \& R systems. Section 3 explains in detail the development of the methodology that applies the parabola method. Section 4 describes the case study where the methodology described is applied. Section 5 presents the results in detail. Section 6 discusses the advantages and limitations regarding the parabola's orientation to each approach used. Finally, the conclusion section describes the limitations, main results, and future research.

\section{Literature Review}

As is widely considered, $P$ \& R systems have played an essential role in the encouragement of the shift of passengers from private vehicles to public transportation [12,13,15-21]. Therefore, the facility's location is close to the public transport system stops. As a consequence, the P \& R system is studied as a mode of transport that includes aspects such as demand, modal distribution, location, and catchment area [22-24]. Thus, in the literature review, a component that is part of the P \& R system's transportation 
planning is the catchment area [25]. The following narrative describes the research carried out in the catchment area of the P \& R system.

The catchment area is a fundamental component in a comprehensive study of the city's urban mobility, which requires the planning of a P \& R system. Actually, it is the starting point to obtain an idea of the potential range of the coverage area of each facility [26]. Cabrera-Barona et al. [27] conducted a study to measure accessibility in healthcare systems. The author employed geographical information to identify and investigate health inequalities and to support policy development. A similar study was conducted by Delamater et al. [28] in which the area of coverage of health services was identified through a geographical context. Thus, the catchment area varies in size and shape, depending on the approach or methods used for its study; these methods vary from a geometric to a mathematical model or even a combination of both [29]. Noskov et al. [30] used Web-GIS to collect maps that serve as benchmarks for transport systems and proposed a quality analysis of the maps based on comparative approaches. The visual complexity of the signs on a map is taken into account in the design of navigation-oriented maps, identifying the coverage area of a P \& R system and the location of information signs [31]. In fact, the majority of authors have investigated the catchment area through the use of a geometric shape such as a parabola, circle, and hyperbola, and thus the equations corresponding to these geometric shapes have also been used [32,33]. The geometric shape that a circle or hyperbola adopts is associated with the radius of the figure. In fact, the method of the circle or the hyperbola cannot provide an orientation of the figure, and therefore a more in-depth study of these figures is not relevant. Several researchers applied the parabola method because of the advantage over other methods of giving the orientation of the figure.

Nevertheless, the geometric shape in which the orientation may vary corresponds to the parabola. Therefore, one of the most commonly used geometric shapes that include all these parameters to study the catchment area of a P \& R system is the parabola method. One of the earliest contributions that used the parabola method in the study of the catchment area of the P \& R system was made by Turnbull et al. $[34,35]$. The author described how to plan a P \& R system throughout the urban area of a city. This study was prepared as a guide for the study of the principles components that a P \& R system should have in order to be implemented. One of these components is the study of the catchment area, which was defined as a geometric figure that is shaped by the parabola. The most interesting aspect is that the parabola is oriented according to the major center of economic activity. Dickins [29] applied the parabola method in order to study the catchment area of light rail transit (LRT) stations. In fact, the parabola method was applied to the P \& R system and the LRT stations. The result provided a combined approach to analyze the catchment area of the LRT stations and the P \& R system. The parabola's orientation in its study was determined according to a theoretical analysis of the direction of public transport for the LRT station, and for the P \& R system according to the LRT station.

Hence, the parabola approach is described as a method widely used in the study of the catchment area of the P \& R system. In addition, a comprehensive analysis leads to the identification of the components of the parabola, such as the focus, the vertex, and mainly the aperture orientation. Three elements are essential to be able to represent the parabola in an urban environment. An element of the parabola known as the focus is the location of the P \& R system, and therefore there is the same number of parabolas as the number of facilities or installations in a P \& R system. A second element is the directrix that represents the station of a public transport system. Thus, a third element is added called the vertex, which is equidistant from the P \& $\mathrm{R}$ and the public transport station. Furthermore, given the focus and directrix, the parabola equation can be found [36].

The parabola's orientation is a fundamental part of this research. Through the literature described, the researchers who have adopted the parabola method for the study of the catchment area of the $\mathrm{P} \& \mathrm{R}$ system have concluded that its orientation is a function of the major commercial activity area or the CBD. This approach is adopted based on the concept of $P \& R$, in which all potential users have a common destination. In reality, not all users travel to the same destination. However, most users 
would choose the main street to reach the facility. In addition, since the components of the parabola have already been determined and these components are integrated into the equations, therefore in order to identify the coverage area, this catchment area needs to be visualized, and its position in the urban area observed. For this purpose, a tool should be used that permits the use of a software program with GIS, similar to the methods used in previous studies in various areas corresponding to transport planning [37-41]. Thus, Farhan et al. [42-44] proposed the parabola method for the study of the catchment area of the P \& R system. The author used the parabola equations and costs to determine a market area that produces a facility and applied its method through GIS software. In addition, the parabola's orientation in its study is determined through the approach described by Turnbull, which is in accordance with the major activity center (CBD).

In our review of the scientific literature that concerns the use of the parabola method in transportation engineering of $\mathrm{P} \& \mathrm{R}$ systems, we found several studies that have been done using its equations, its elements, and how these elements have been made visible through a GIS tool. Nevertheless, at the same time, the studies use a common approach to the parabola's orientation. Therefore, by developing a more in-depth approach to the parabola orientation, it would be possible to understand whether the catchment area varies in its coverage radius and also whether the location of the facilities is not overestimated. Thus, identifying the parabola orientation implies developing a comprehensive study that includes the equations and the elements to be drawn in a GIS tool.

Our study aimed to develop a software program within a GIS tool that includes the use of the parabola's equations and elements. In addition, it aimed to modify the parabola orientation based on two approaches: first, the parabola orientation using the Turnbull concept, which is according to the center of major commercial activity area or CBD; and second, the parabola orientation approach according to the main access of the facility. Using these two approaches, it was possible to visualize and establish the coverage rate of the catchment area of the P \& R system over the areas of a city.

\section{Method Description}

This section describes the main points and the steps that constitute the modeling of a geometric figure, such as the parabola, which symbolizes the catchment area of a P \& R system in an urban environment. The first task is defining the parabola's elements as its vertex, focus, and directrix, and linking them to the P \& R system's components. Then, an approach to formulation analysis is made, in other words, a detailed explanation of how to use them together with the variables in order to model the parabola. It also indicates how to include the formulas and the set of variables in the construction of a software program. Finally, a software script within a GIS tool is developed by using a programming language, which enables the parabola shape to be visualized in the urban environment.

Based on our research and the development of the method, two alternative scenarios for the use of the parabola method were proposed:

(i) the first is based on the parabola's orientation according to the major commercial activity (CBD), and

(ii) the second approach is that proposed in this research, in which the parabola's orientation is determined according to the main access to the facility.

\subsection{Parabola Elements Linked to $P \& R$ System Components}

A parabola is a set of points on a plane that is an equal distance from a given point and line. Thus, the point is called the parabola's focus, and the line is called the directrix. These elements of the parabola are the initial argument of the methodology, and the P \& R system components in an urban environment are linked to them. In order to have a general idea of the elements of the parabola linked to the P \& R system, they are described on an abstract non-mathematical level in the following bullet list and Figure 1: 
- Focus: This is the fixed point. In our model, these are the coordinates of each installation of the P \& R system.

- Vertex: This is the middle point of the intersection of the axis with the parabola. This point is $(\mathrm{h}, \mathrm{k})$, and it is explained in the section equations.

- Axis: The straight-line perpendicular to the generator that goes through the focus is called the axis. It is the axis of symmetry of the parabola.

- Directrix. The directrix is perpendicular to the axis of symmetry of a parabola.

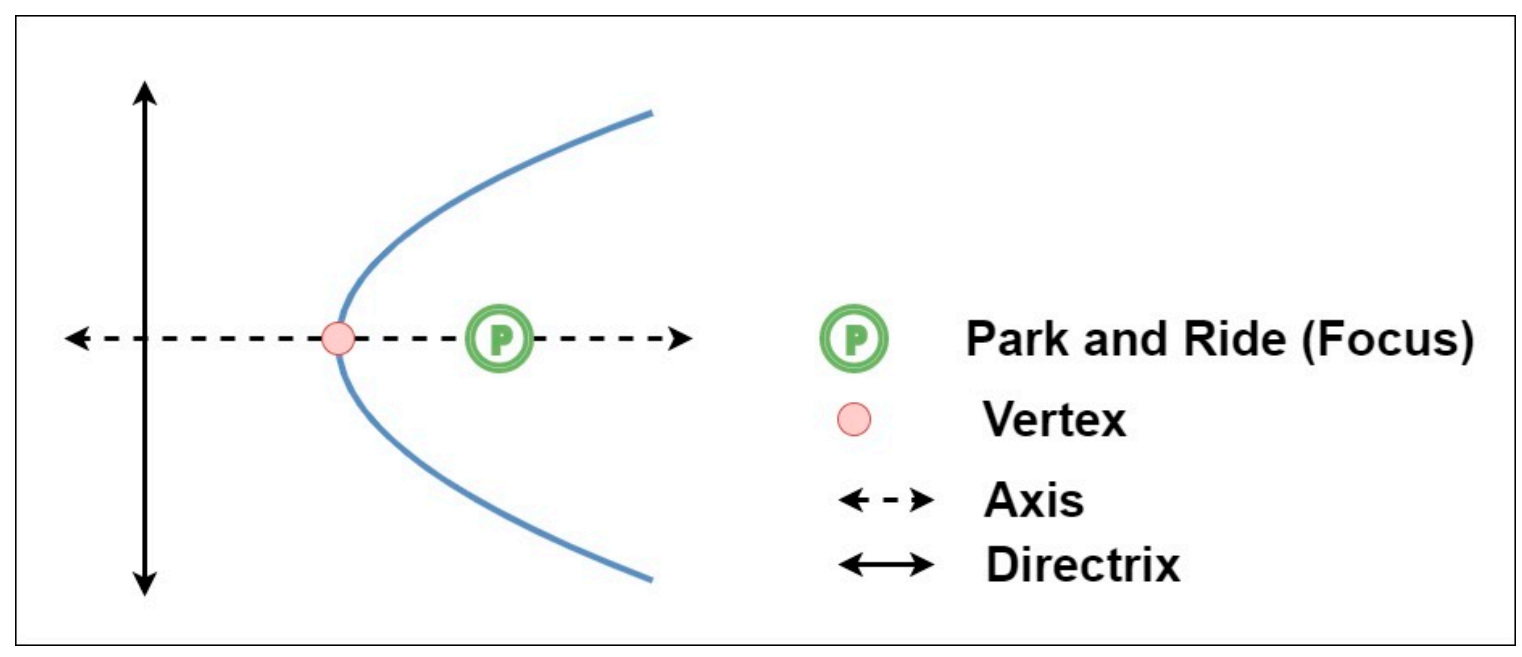

Figure 1. Illustration of the elements of the parabola.

\subsection{Equations}

The parabola is defined as a simple geometrical shape that can be described by a set of equations. At the same time, these equations can be utilized to define the catchment area of a P \& R system's stations in an urban environment. The following equations build the parabola:

$$
\begin{aligned}
& (x-h)^{2}=4 p(y-k) \\
& (y-k)^{2}=4 p(x-h) .
\end{aligned}
$$

In both cases, $\mathrm{h}$ and $\mathrm{k}$ represent the vertex, and the focus is the coordinates of the P \& R system $(p+h, k) ; \mathrm{p}$ is a point that is part of the focus. Given the focus and the directrix of a parabola, we can find the parabola's equation. The difference between (1) and (2) is the opening of the parabola. In our case, we can use either of the two equations due to the parabola orientation that is determined by the approach of the P \& R system previously described. The following Table 1 shows the variables and the set of equations used to model a parabola.

Table 1. Collection of equations and variables that define the parabola.

\begin{tabular}{ccc}
\hline Equation & $(\boldsymbol{y}-\boldsymbol{k})^{2}=4 \boldsymbol{p}(\boldsymbol{x}-\boldsymbol{h})$ & $(\boldsymbol{x}-\boldsymbol{h})^{2}=4 \boldsymbol{p}(\boldsymbol{y}-\boldsymbol{k})$ \\
\hline Vertex & $(h, k)$ & $(h, k)$ \\
\hline Focus & $(p+h, k)$ & $(h+p, k)$ \\
\hline Directrix & $x=-p+h$ & $y=-p+k$ \\
\hline Axis of symmetry & $y=k$ & $x=h$ \\
\hline$p>0$ & Opens to the right & Opens upward \\
\hline$p<0$ & Opens to the left & Opens downward \\
\hline
\end{tabular}




\subsection{Orientation of Parabola}

The parabola's orientation is based on two approaches. On the one hand, the traditional approach is described in the literature review in which the parabola is oriented according to the major business activity at CBDs. The second approach and according to our research, the parabola is oriented according to the main access route to reach the facility.

In order to describe the first approach in which the parabola's orientation is in accordance with the main center of activity (CBD), Figure 2 shows this theoretical approach to the traditional parabola orientation in order to establish the catchment area of the P \& R system in the urban area of a city. Thus, the central business district (CBD), the P \& R system, and the catchment area shown by the parabola are contrasted, as well as the arrows representing the route of a public transport system from the facility to the CBD. The literature describes the parabola's orientation as symmetrical to the central business district (CBD) and reached through public transportation.

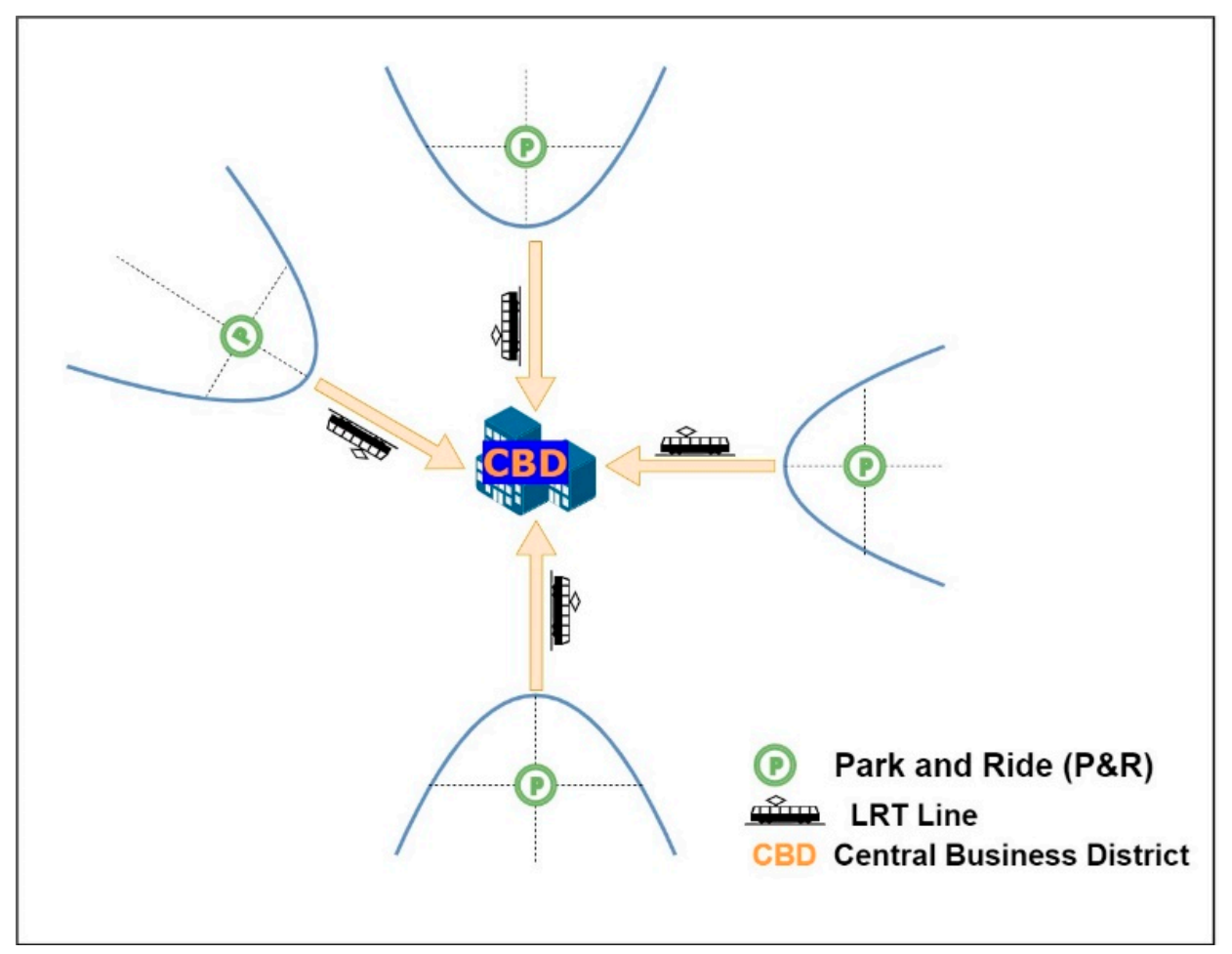

Figure 2. Illustration of parabola orientation based on major business activity.

In the light of this new approach, a hypothesis emerges; the coverage area within the urban environment varies and, in a more realistic form, can represent the catchment area of the facility. Therefore, Figure 3 represents the theoretical analysis of this new approach. The graph shows the P \& R system of a hypothetical city with four P \& Rs, and it is possible to note that while the orientation varies, the same destination is kept where potential users of the $P \& R$ system arrive via public transport to the CBD.

Finally, a comparison of the approaches to the parabola's orientation is presented in Figure 4. Using these theoretical concepts, programming code was developed that allowed us to express it in a real situation in order to be able to identify the advantages and limitations of each particular approach. Both approaches maintained the concept of $\mathrm{P} \& \mathrm{R}$, which consists of driving a certain distance in a private vehicle and then using the $\mathrm{P} \& \mathrm{R}$ system to change to public transport to reach the destination. 


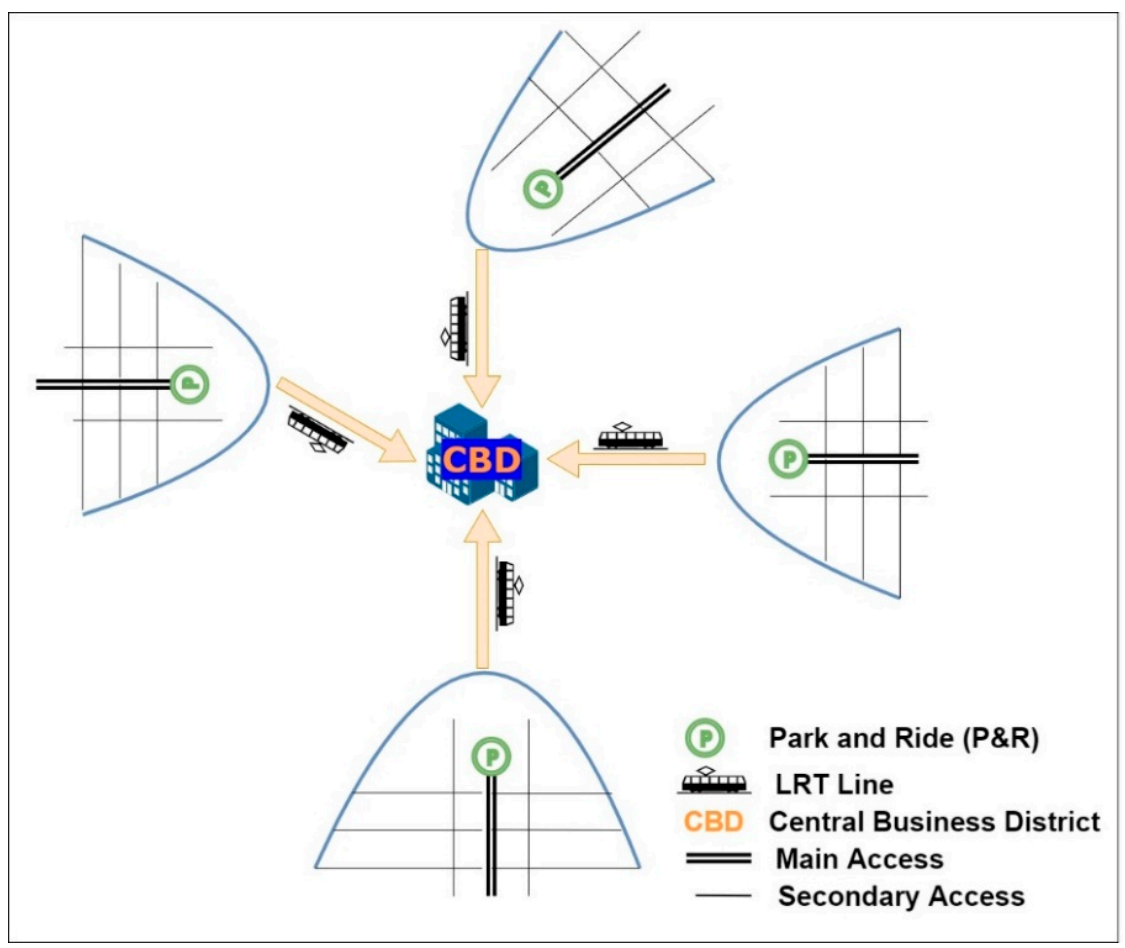

Figure 3. Illustration of the parabola's orientation based on the main access to the facility.

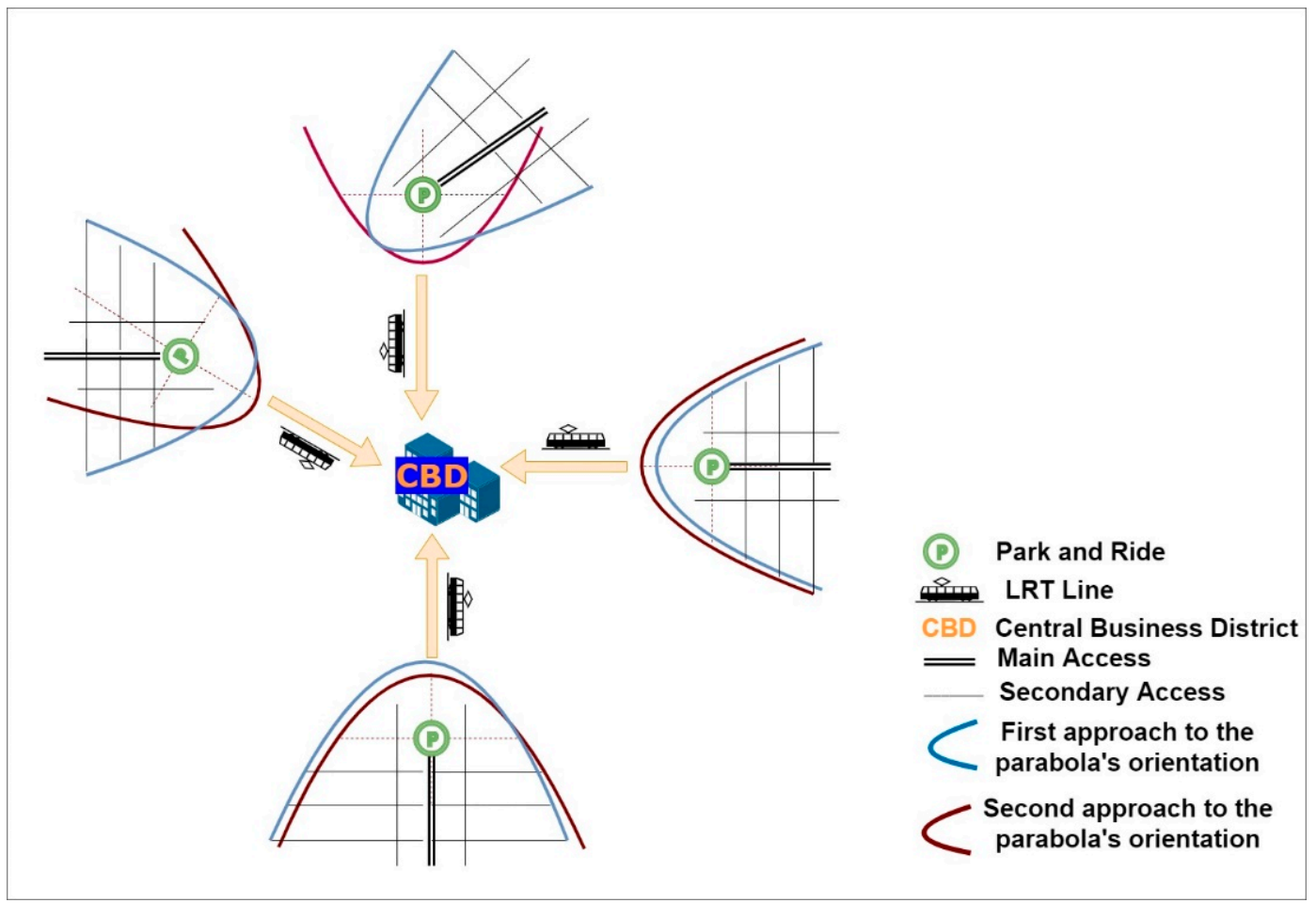

Figure 4. Illustration of the parabola's orientation based on comparing both approaches.

\subsection{Flow Chart Developed for the Parabola Method}

In order to show the variables and components of the $\mathrm{P} \& \mathrm{R}$ system in the mathematical equations and include the parabola orientation and finally its visualization through GIS software, a flow chart including the software program is shown in Figure 5. 


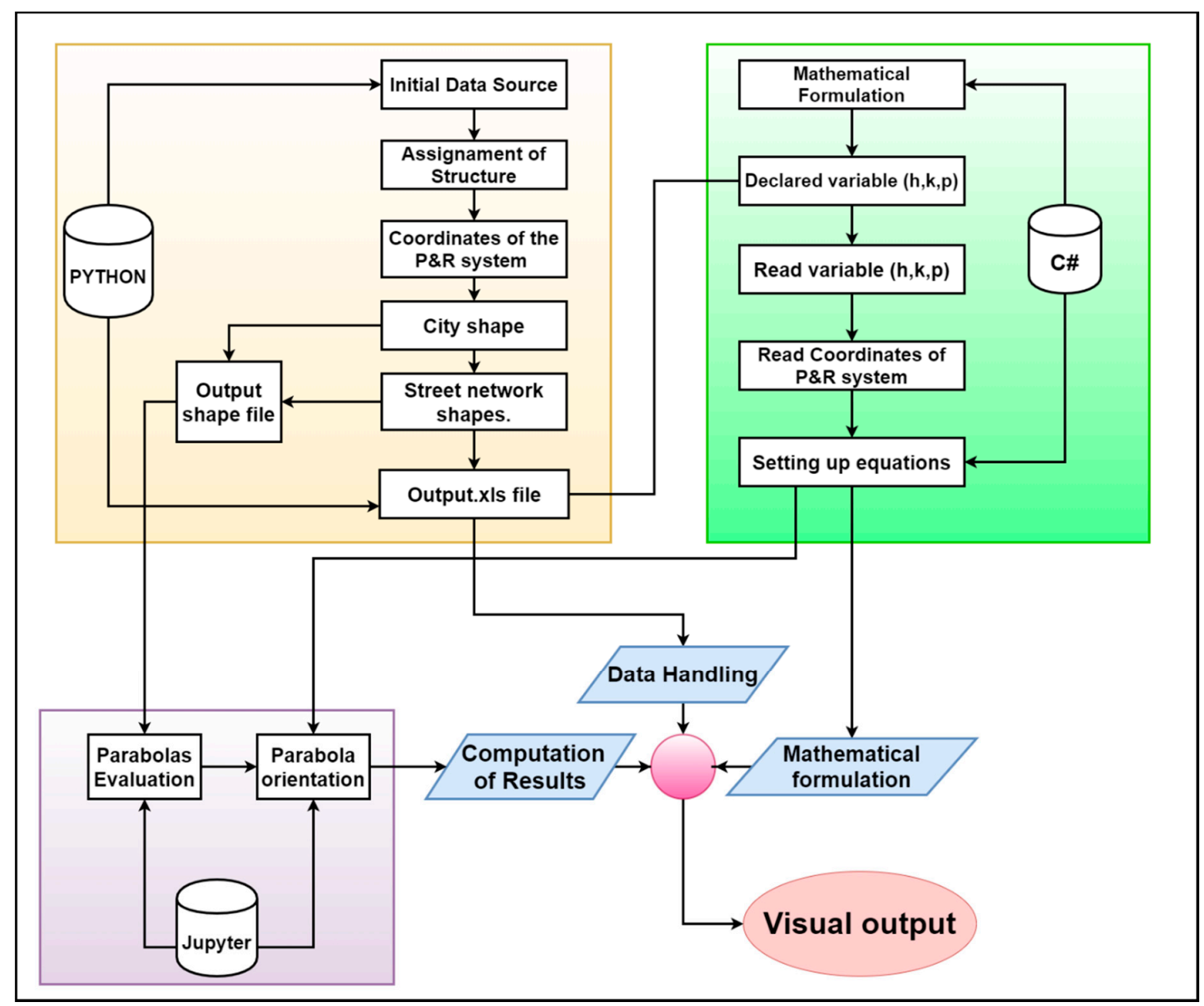

Figure 5. Representation of the flow chart for the parabola method.

We used Python and Jupyter Notebooks to develop an implementation of the two parabola methods described above. In addition, several standard libraries were utilized, namely numpy, geopandas, pandas, osmnx, pyproj, shapely, network, geopy.geocoders, and matplotlib.

Data Handling: This section is described as the data input of the methodology. This data is input and read through the software program. The location coordinates of the P \& R system are entered. In addition, the urban area shape of the city and the road system shape is loaded. The result is used to generate input into two sections: in the first section, the mathematical model and the variables that are to be input in the equations, and in the second section's simulation of results to visualize the parabola.

Mathematical formulation: In this section, using the software program, the variables of the mathematical model are defined, and then the data from the data source section are input and loaded into the parabola equations. The results obtained work as data that are input in the simulation results section.

Computation of Results: The simulation section uses data from two sections, one from the data source and the other from the mathematical model section. In this section, the parabola orientation is defined. For our case, the parabola orientation is provided according to the approaches described previously.

Finally, the parabola that illustrates the catchment area of the P \& R system is shown over the urban area of the city. The results would depend on various factors, such as the type of city and the facility location. However, the methodology developed can be reproduced for different types of cities and various facility locations. Our study aimed to present a novel approach to the parabola orientation and compare it with the traditional approach to identify the limitations, advantages, and differences. 


\section{Case Study}

In order to apply our approach to the parabola's orientation, a real case was chosen, which is the city of Cuenca in Ecuador. Cuenca is the third-largest city in Ecuador in terms of population and is located in the south of the country. It is considered one of the best-managed cities in Ecuador and South America in the field of transport. The most notable project that has been developed is the Mobility and Public Spaces Plan, which outlines the transport policies for the coming years. In addition, one of the established projects is implementing a new transport system such as the LRT. This system will connect some urban areas to the CBD. As general information, Cuenca is formed by 15 urban areas, and each area is divided into neighborhoods separated by local streets. The historical center is typically Latin American, where it serves as a commercial center, in contrast to European cities, where they are generally separated. One of the problems is the high level of congestion in the city center, which is classified as a World Heritage Site by UNESCO. Some policies have been developed to alleviate this problem. Orellana et al. [45] conducted several studies in the area of mobility. The author contributed with studies on the effect of the spatial configuration of the street networks on the mobility of the users of bicycles through a tracking application, using information from the multiple sources of OpenStreetMap and Strava Metro. Furthermore, Hermida et al. [46] conducted studies on the influence of the built urban environment on the pedestrian flow in the intermediate Latin American city, Cuenca, Ecuador. The author analyzed how the physical and spatial characteristics of the streets, sidewalks, land use conditions, and occupation influence the number of pedestrians. However, few policies are in place for users who come daily from out of town by private vehicles and wish to go to the city center in a more friendly transport mode such as LRT. For this problem, in a previous study, Ortega et al. [11] developed a set of seven P \& R facilities that establish their location through each facility's capacity. The P \& R system's planning process consists of determining the coverage area that these facilities could have in the urban area. Thus, one of these methodologies is the parabola, although due to the subdivision of the zones, each of these facilities would have the main access, which is the parabola rotation. The authors are developing a project on the P \& R system, and one of the contributions is to determine the catchment area. For a better explanation of the P \& R system (designed A to G), the $10 \mathrm{~km}$ LRT system, and the city areas (designated 1 to 15), Figure 6 is shown.

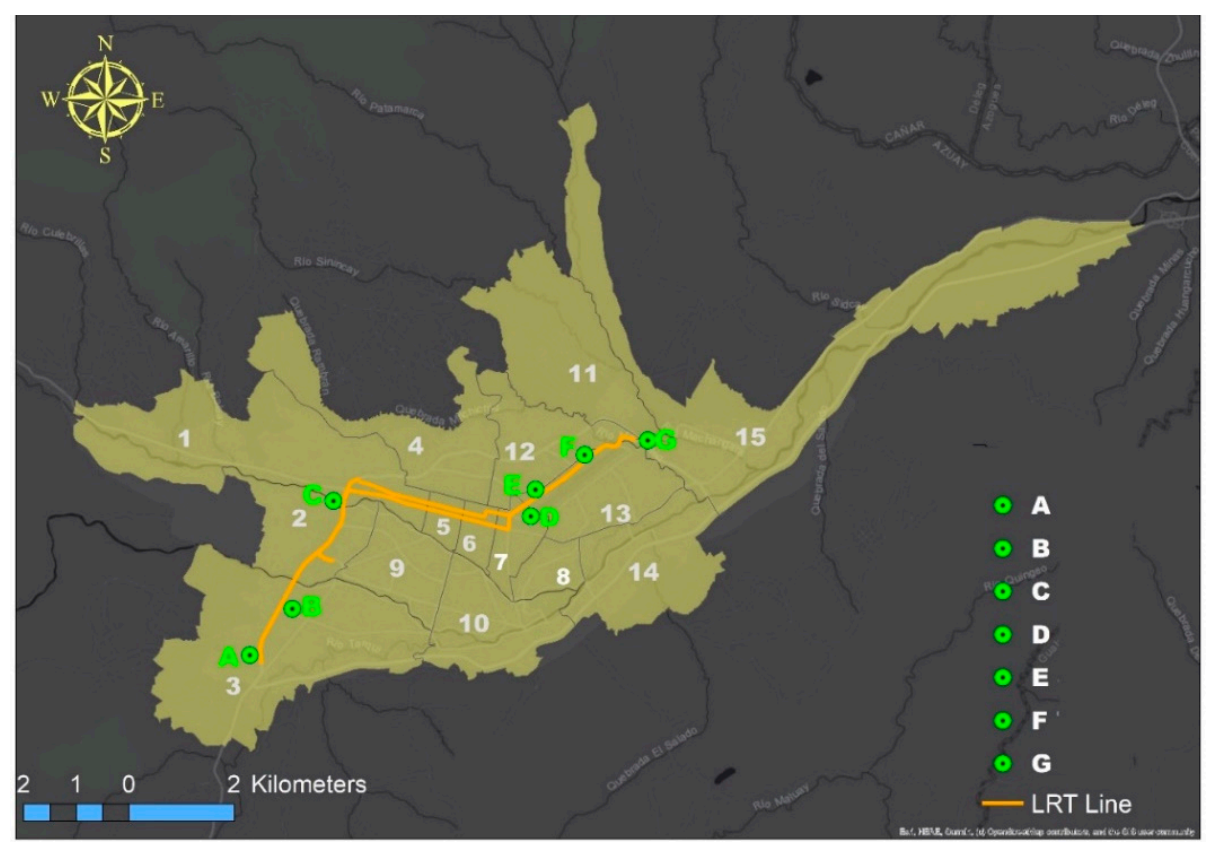

Figure 6. The city of Cuenca, Ecuador, with the LRT system and P \& R. 


\section{Results}

In this section, the results obtained show the two approaches to the parabola's orientation according to the methodology developed and described previously. Thus, two maps are provided as a result of the use of the software, each map illustrating an approach to the parabola's orientation. The first map is the approach to the parabola's orientation, according to the CBD. The second map is the parabola orientation, according to the main access to reach the facility. In our case study, there are seven hypothetical facilities of a P \& R system (designated from A to G) that were suggested in the study by Ortega et al. [11]. The result is the set of parabolas on the city map that also indicates the catchment area of the P \& R system and lets us see the area that they cover over the 15 urban zones of the city.

The map that is shown in Figure 7 corresponds to the approach in which the parabola's orientation is according to the major business center or CBD. In our case study, the facilities of the P \& R system achieved the purpose of covering specific areas of the urban area of the city. However, there were a significant number of urban areas not covered by the P \& R system's catchment area. An assumption was made, which means that potential users of the $\mathrm{P} \& \mathrm{R}$ system in those areas would not be willing to use those facilities. Simultaneously, for facilities designated as D, E, F, and G, their catchment areas would cover the same urban areas; thus, these areas would be overcovered. Facilities A, B, and C, on the other hand, would have better distribution. These three facilities together served the purpose of covering an extensive urban area without overlapping. The distribution of the P \& R system facilities provided a measure of how close the facilities were to each other or whether it was necessary to implement new facilities to cover all the urban areas of a city.

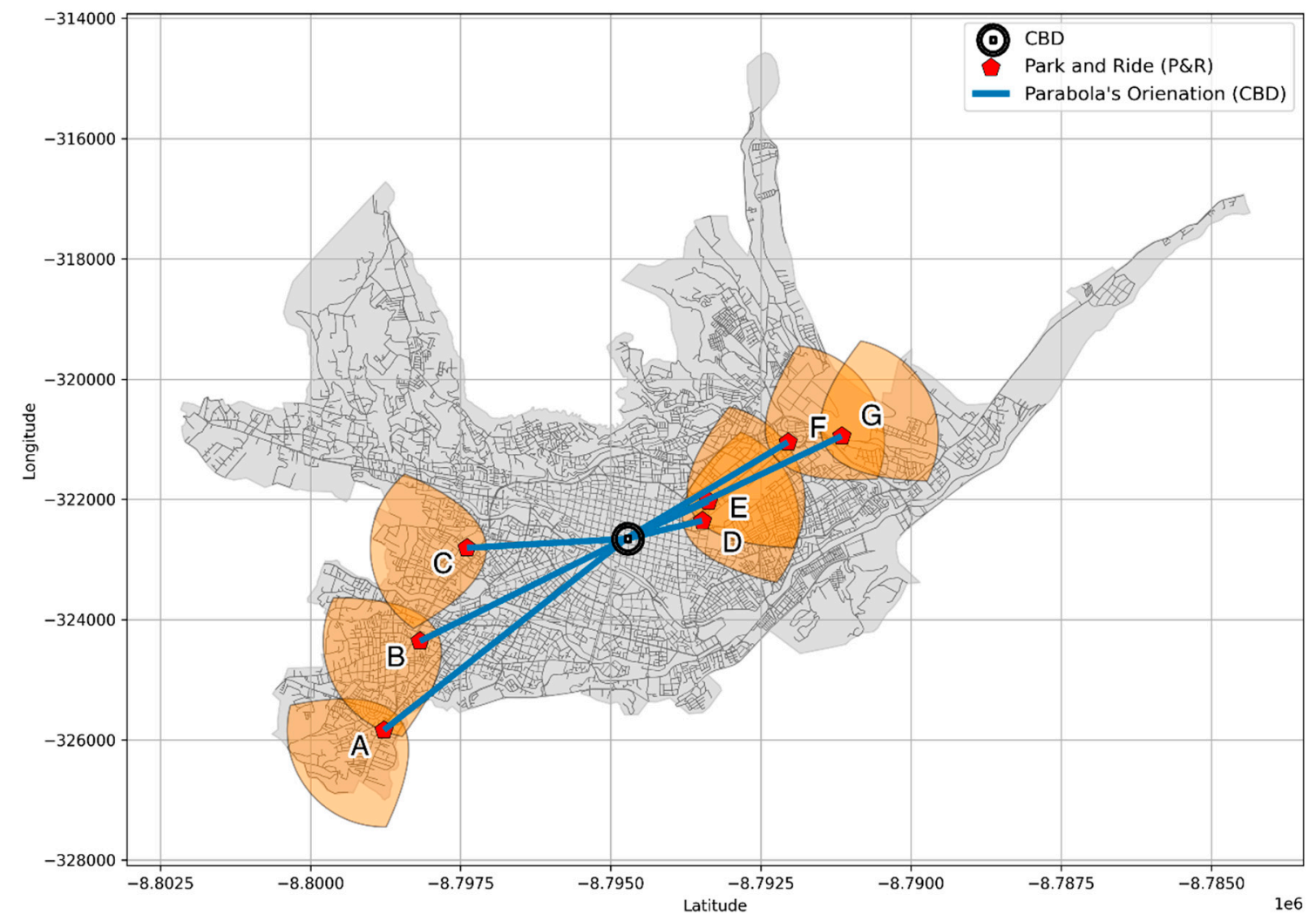

Figure 7. The result of using the parabola method based on orientation according to the center of major activity.

Figure 8 shows the result of the catchment area of the P \& R system facilities according to the approach adopted, which is the parabola orientation according to the main access to reach the facility. The result shows that the P \& R system's catchment area was better distributed in the city's urban areas. Potential users of the P \& R system who were not previously within this catchment area would actually 
now be within the catchment area and would be willing to use the facilities. The most significant fact is that the catchment areas of facilities designated as D, E, F, and G were not overlapping. Therefore, this approach is more realistic, considering the point that users will use the main access to reach the facility and have a common destination, the CBD. However, it should also be mentioned that the P \& R system would not cover some urban areas. This can be explained by the locations of the P \& R system facilities and the need to implement a more number of facilities.

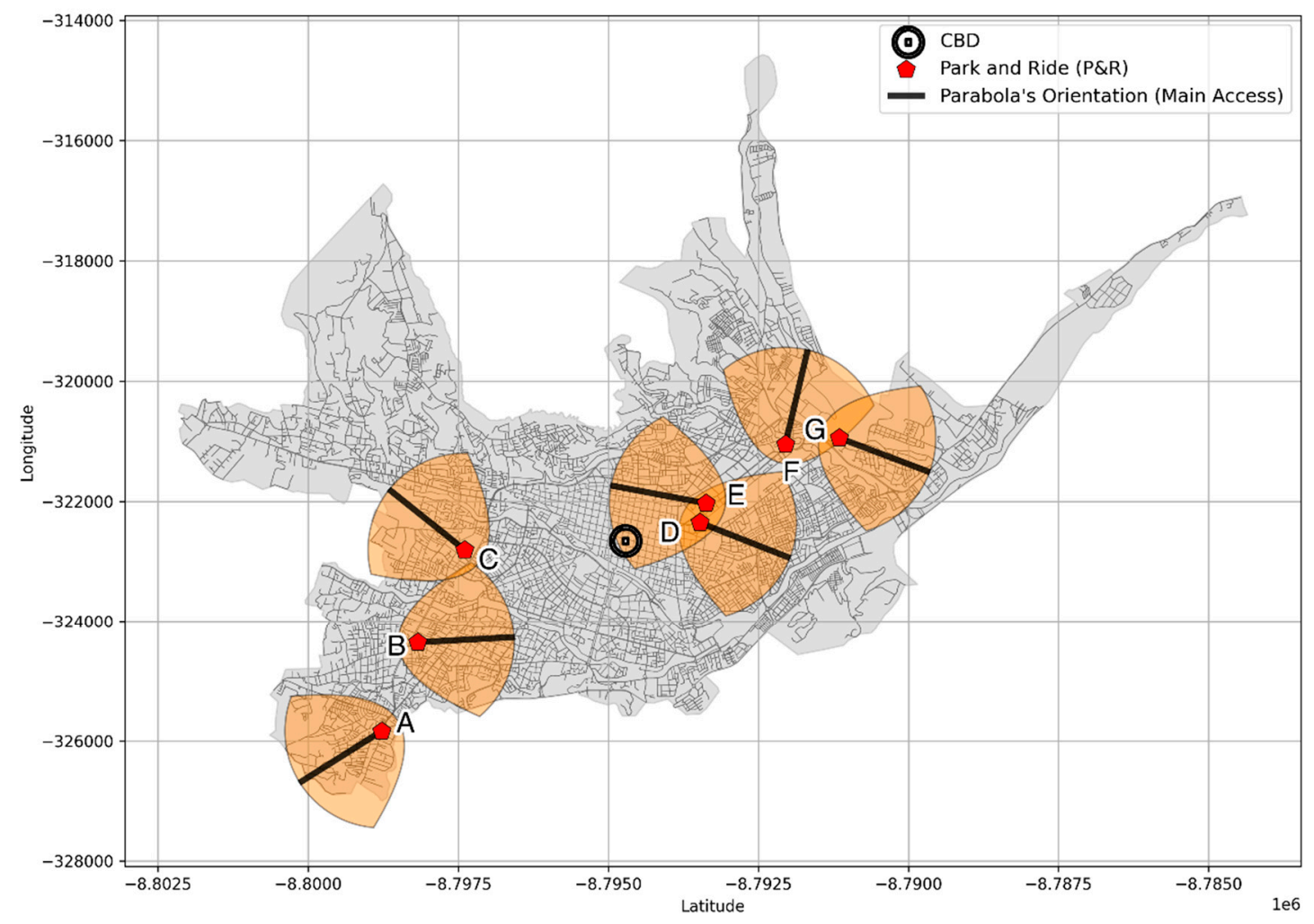

Figure 8. The result of using the parabola method based on orientation according to the main access.

The P \& R system was created to allow users who travel to the city center in private vehicles to change their mode of transport to a more friendly mode, such as public transport. Thus, private vehicle users whose starting point is on the outskirts of the urban area of the city or in areas distant from the city center frequently use their vehicles and then park their vehicles in the P \& R system to change to public transport to reach their destination, which is the CBD or the city center. Emphasizing the importance of this concept indicates that potential users always have a common destination through a public transport route, which leads to the traditional approach of parabolic orientation, which in this study is the first scenario. However, potential users of the P \& R system arrive at the facility from the main access street, which leads to a new orientation of the parabola corresponding to the second scenario. To highlight that, in both the first and the second scenario, the destination is the same; however, it is more realistic to consider the orientation of the parabola as the second scenario because the user accesses the installation from the main access street. According to the results, the first scenario permits affirmation that there are a considerable number of facilities in the P \& R system in the city, and even the catchment areas overlap each other, and that their locations are very close to each other. In the second scenario, the proposed $\mathrm{P} \& \mathrm{R}$ is distributed so that there is no need to reduce them in quantity because their catchment area covers almost all areas of the city. Even to cover the missing areas, two additional facilities could be located, one in the north and one in the south. Therefore, the second scenario proposed in this article gives a more accurate view of the actual scope of coverage of a P \& R system and covers the concept of P \& R mentioned at the beginning. 
The subsequent section discusses the results obtained using the methodology developed and the advantages and limitations of each approach.

\section{Discussion}

In both proposed scenarios, the methodology described in this article has been used, the result being a solid methodology to represent the catchment area of the $\mathrm{P} \& \mathrm{R}$ system. In addition, the approach about the parabola orientation that we have proposed is compared with the traditional concept of the parabola orientation. Thus, we can describe in detail each proposed scenario, such as its advantages and its limitations. In general, both scenarios cover areas of the city; however, according to the orientation, the covered areas are different.

Approach one considers the parabola's orientation according to the major business activity or CBD. Based on this traditional approach, the P \& R system's catchment area covers the eastern and western parts of the city, but the northern and southern areas are not covered. This means that potential users who come from this location do not use the P \& R system. In addition, there is an overlap of the catchment areas (parabolas) between them, and there is coverage of multiple facilities in the same area. Therefore, there is an over coverage of some areas and a non-existent coverage of the P \& $\mathrm{R}$ system in certain areas.

Regarding the second approach in which the parabola orientation is according to the main access to reach the facility, the coverage area is better extended than in the previous approach. Furthermore, the coverage area of the $\mathrm{P} \& \mathrm{R}$ system is not overlapping. This approach is more in line with the reality and operation of the catchment area of a P \& R system. In fact, it leads to evidence that a major number of potential users of the $\mathrm{P} \& \mathrm{R}$ system could be considered. However, some zones of the city are not covered. Therefore, the $\mathrm{P} \& \mathrm{R}$ system facilities require reconfiguration according to their location in order to cover most of the urban areas of the city.

The parabola method to determine the catchment area of the P \& R system is a tool that helps transportation planners understand whether the location of $P \& R$ system facilities covers most of the city's urban area. Furthermore, the method helps to verify that the same P \& R facility does not cover the same zone. In Latin American cities where this concept is relatively new, it is essential to make an accurate analysis of the location of potential or existing facilities that allow connection to public transport. In fact, few solutions have been given to those who come from remote places or outside the urban area of the city and use private vehicles because of the distance of the journey. A method that helps to encourage private vehicle users to switch to public vehicles is identified as the P \& R system. In transport planning, the P \& R system can be considered a transport mode, and as with any transport mode, the first study to be carried out is to determine the catchment area. However, in future studies, transportation planners must link this method and add demand, accessibility measurements, trip generating points, and the interaction of the P \& R system with public transportation. One of the limitations is that this method was applied to a set of facilities that are connected to a single public transport system network such as the LRT. However, applying this method to the different public transport lines that cover a city (e.g., bus, metro, LRT) and that are connected to the P \& R system could help to understand precisely the P \& R system's catchment area. In addition, the type of city configuration and the number of $\mathrm{P} \& \mathrm{R}$ system facilities impacts on the study of the $\mathrm{P} \& \mathrm{R}$ system catchment area in an urban area. However, this new approach to the parabola orientation opens the door to new P \& R studies, mainly because of its easy implementation, which makes it a useful tool for cities that want to implement a P \& R system. Thus, transport planners can determine the catchment area of each facility in advance of its implementation. In addition, further research on adding new parameters to this parabola methodology leads to the development of a more accurate model.

\section{Conclusions}

Our research about the P \& R system's catchment area indicates that the parabola method is a methodology widely used by the authors to study the P \& R system's catchment area but with 
an exclusive orientation approach. The current research aims to extend this method and propose a new approach to the orientation of the parabola that is traditionally based on the major business district or CBD. Therefore, the contribution of this study is to analyze the traditional orientation and, at the same time, the new orientation, in order to determine which provides better results in terms of coverage area in the urban environment. Furthermore, the development of this model is composed of a set of mathematical equations, which through a software program and the use of GIS, allows for the simulation of a set of parabolas in the urban environment of the city.

Regarding our research concerning the parabola's orientation in the P \& R system's catchment area, the first approach results in the conclusion that some catchment areas cover the same area of a city's urban area, mainly when the facilities are at a close distance from each other. In the second approach, the parabola's orientation is determined according to the main access to reach the facility and leads to a better result. It prevents overlapping of the coverage area in the same area and a more realistic interpretation of the purpose of the catchment area. However, a major conclusion is that our methodology is a useful tool for transport planners to configure the P \& R system catchment area in an urban environment.

As mentioned, the second approach provides better results than the traditional approach based on the parabola method to determine the catchment area of the P \& R system over the urban areas of a city. In our case study, the results concern a medium-sized city. However, the city's configuration, and the number and location of facilities could change the coverage area. The aim, after all, is the same, which is to understand how to model this catchment area using the parabola method in an urban environment.

Our methodology in future research is appropriate for application in different configurations regarding the types of cities that wish to implement a P \& R system and also develop a study of P \& R systems, including connections to transport modes (e.g., buses, railways, subways). Transportation planners and researchers consider that the $\mathrm{P} \& \mathrm{R}$ system's catchment area is a fundamental component for the integral development of a P \& R system study. Therefore, the authors of this study are currently working on this line of research.

Author Contributions: All authors have contributed to the development of this article. All authors have read and agreed to the published version of the manuscript.

Funding: This research received no external funding.

Acknowledgments: We thank the Cuenca Municipality, which provided sources such as digital cartography, data, and layers through the Sustainable Mobility Plan.

Conflicts of Interest: The authors declare no conflict of interest.

\section{Scenario Codes and P \& R Location}

The following Scenario codes and P \& R location data are available in the repository of this journal:

Scenario one

Scenario two

P \& R location

\section{References}

1. Ibrahim, A.N.H.; Borhan, M.N.; Rahmat, R.A.O. Understanding Users' Intention to Use Park-and-Ride Facilities in Malaysia: The Role of Trust as a Novel Construct in the Theory of Planned Behaviour. Sustainability 2020, 12, 2484. [CrossRef]

2. Afandizadeh, S.; Abdolmanafi, S. Development of a Model for a Cordon Pricing Scheme Considering Environmental Equity: A Case Study of Tehran. Sustainability 2016, 8, 192. [CrossRef]

3. Holguín-Veras, J.; Reilly, J.; Aros-Vera, F.; Yushimito, W.F.; Isa, J. Park-and-Ride Facilities in New York City. Transp. Res. Rec. J. Transp. Res. Board 2012, 2276, 123-130. [CrossRef]

4. Cornejo, L.; Perez, S.; Cheu, R.L.; Hernández, S. An Approach to Comprehensively Evaluate Potential Park and Ride Facilities. Int. J. Transp. Sci. Technol. 2014, 3, 1-18. [CrossRef] 
5. Duncan, M.; Christensen, R.K. An analysis of park-and-ride provision at light rail stations across the US. Transp. Policy 2013, 25, 148-157. [CrossRef]

6. Flamm, B.J.; Rivasplata, C.R. Public Transit Catchment Areas. Transp. Res. Rec. J. Transp. Res. Board 2014, 2419, 101-108. [CrossRef]

7. Ortega, J.; Tóth, J.; Péter, T. A Spatial Study of the Catchment Area of P \& R Facilities. In Proceedings of the X. International Conference on Transport Sciences Győr 2020, Győr, Hungary, 26-27 March 2020; p. 20.

8. Murray, A.T. Advances in location modeling: GIS linkages and contributions. J. Geogr. Syst. 2010, 12, 335-354. [CrossRef]

9. Macias, K. Alternative Methods for the Calculation of Pedestrian Catchment Areas for Public Transit. Transp. Res. Rec. J. Transp. Res. Board 2016, 2540, 138-144. [CrossRef]

10. Andersen, J.L.E.; Landex, A. Catchment areas for public transport. In WIT Transactions on the Built Environment; WIT Press: Southampton, UK, 2008; Volume 101, pp. 175-184.

11. Ortega, J.; Tóth, J.; Péter, T. Estimation of Parking Needs at Light Rail Transit System Stations. In Proceedings of the Conference on Transport Sciences 2019, Gyor, Hungary, 22-23 March 2018; p. 8.

12. Ortega, J.; Hamadneh, J.; Esztergár-Kiss, D.; Tóth, J. Simulation of the Daily Activity Plans of Travelers Using the Park-and-Ride System and Autonomous Vehicles: Work and Shopping Trip Purposes. Appl. Sci. 2020, 10, 2912. [CrossRef]

13. Ortega, J.; Tóth, J.; Péter, T.; Moslem, S. An Integrated Model of Park-And-Ride Facilities for Sustainable Urban Mobility. Sustainability 2020, 12, 4631. [CrossRef]

14. Ortega, J.; Tóth, J.; Moslem, S.; Péter, T.; Duleba, S. An Integrated Approach of Analytic Hierarchy Process and Triangular Fuzzy Sets for Analyzing the Park-and-Ride Facility Location Problem. Symmetry 2020, 12, 1225. [CrossRef]

15. Moyano, C.M.; Ortega, J.F.; Mogrovejo, D.E. Efficiency Analysis during Calibration of Traffic Microsimulation Models in Conflicting Intersections Near Universidad del Azuay, using Aimsun 8.1. In Proceedings of the MOVICI-MOYCOT 2018: Joint Conference for Urban Mobility in the Smart City, Medellin, Colombia, 18-20 April 2018.

16. Holguı́n-Veras, J.; Yushimito, W.F.; Aros-Vera, F.; Reilly, J.J. User rationality and optimal park-and-ride location under potential demand maximization. Transp. Res. Part B Methodol. 2012, 46, 949-970. [CrossRef]

17. Zijlstra, T.; Vanoutrive, T.; Verhetsel, A. A meta-analysis of the effectiveness of park-and-ride facilities. Eur. J. Transp. Infrastruct. Res. 2015, 15, 597-612.

18. Parkhurst, G.; Richardson, J. Modal integration of bus and car in UK local transport policy: The case for strategic environmental assessment. J. Transp. Geogr. 2002, 10, 195-206. [CrossRef]

19. Antolín, G.; Alonso, B.; Cordera, R.; Dell'Olio, L. The Effect of Introducing Parking Policies on Managing Mobility to Beaches in Touristic Coastal Towns. Sustainability 2019, 11, 3528. [CrossRef]

20. Mock, A.; Thill, J.-C. Placement of Rapid Transit Park-and-Ride Facilities. Transp. Res. Rec. J. Transp. Res. Board 2015, 2534, 109-115. [CrossRef]

21. Cavadas, J.; Antunes, A.P. Optimization-based study of the location of park-and-ride facilities. Transp. Plan. Technol. 2019, 42, 201-226. [CrossRef]

22. De Luca, G.; Gallo, M. Artificial Neural Networks for Forecasting User Flows in Transportation Networks: Literature Review, Limits, Potentialities and Open Challenges. In Proceedings of the 2017 5th IEEE International Conference on Models and Technologies for Intelligent Transportation Systems (MT-ITS), Naples, Italy, 26-28 June 2017; pp. 919-923.

23. Gallo, M.; De Luca, G. Spatial Extension of Road Traffic Sensor Data with Artificial Neural Networks. Sensors 2018, 18, 2640. [CrossRef]

24. Gallo, M.; Simonelli, F.; De Luca, G.; Della Porta, C. An Artificial Neural Network Approach for Spatially Extending Road Traffic Monitoring Measures. In Proceedings of the EESMS 2016-2016 IEEE Workshop on Environmental, Energy, and Structural Monitoring Systems, Bari, Italy, 13-14 June 2016; pp. 1-5.

25. Mesa, J.A.; Ortega, F.A. Park-and-Ride Station Catchment Areas in Metropolitan Rapid Transit Systems, 48th ed.; Springer: Boston, MA, USA, 2001.

26. Lu, X.-S.; Guo, R.-Y. A Bi-Objective Model for Siting Park-and-Ride Facilities with Spatial Equity Constraints. Promet. Traffic Transp. 2015, 27, 301-308. [CrossRef]

27. Cabrera-Barona, P.F.; Blaschke, T.; Gaona, G. Deprivation, Healthcare Accessibility and Satisfaction: Geographical Context and Scale Implications. Appl. Spat. Anal. Policy 2017, 11, 313-332. [CrossRef] 
28. Delamater, P.L.; Shortridge, A.; Kilcoyne, R.C. Using floating catchment area (FCA) metrics to predict health care utilization patterns. BMC Health Serv. Res. 2019, 19, 144. [CrossRef] [PubMed]

29. Dickins, I.S.J. Park and ride facilities on light rail transit systems. Transportation 1991, 18, 23-36. [CrossRef]

30. Noskov, A.; Zipf, A. Open-data-driven embeddable quality management services for map-based web applications. Big Earth Data 2018, 2, 395-422. [CrossRef]

31. Keil, J.; Edler, D.; Kuchinke, L.; Dickmann, F. Effects of visual map complexity on the attentional processing of landmarks. PLoS ONE 2020, 15, e022957. [CrossRef]

32. Chalermpong, S.; Ratanawaraha, A.; Maneenoy, N.; Chullabodhi, C. User Characteristics and Effectiveness of a Park and Ride Facility in Bangkok. Eng. J. 2018, 22, 1-10. [CrossRef]

33. Hamid, N.A. Delineating catchment areas of selected KTM komuter stations in the kuala lumpur conurbation using a gis-based approach. Arab World Geogr. 2010, 13, 108-125.

34. Turnbull, K.F. Effective Use of Park-and-Ride Facilities; Aboard, T.R., Ed.; National Academy Press: Washington, DC, USA, 1995.

35. Turnbull, K.F.; Evans, J.E.; Levinson, H.S. Park and Ride/Pool: Traveler Response to System Changes; The National Academies Press: Washington, DC, USA, 2004.

36. Sanchez, W.B.; Glassmeyer, D.M. Connecting Parabolas and Quadratic Functions. Math. Teach. 2017, 110, 380. [CrossRef]

37. Murray, A.T. Geography in Coverage Modeling: Exploiting Spatial Structure to Address Complementary Partial Service of Areas. Ann. Assoc. Am. Geogr. 2005, 95, 761-772. [CrossRef]

38. Murray, A.T.; Tong, D. GIS and spatial analysis in the media. Appl. Geogr. 2009, 29, 250-259. [CrossRef]

39. Norlida, A.H.; Jamilah, M.; Mohamed Rehan, K. Parking duration of fringe Park-and-Ride users and delineation of stations catchment area: Case of the Kuala Lumpur conurbation. J. East. Asia Soc. Transp. Stud. 2007, 7, 1296-1310.

40. Tong, D.; Murray, A.T. Maximising coverage of spatial demand for service. Pap. Reg. Sci. 2009, 88, 85-97. [CrossRef]

41. Balchin, P.N.; Isaac, D.; Chen, J. The Spatial Structure of Urban Areas. In Urban Economics; Macmillan Education: London, UK, 2000; pp. 80-126.

42. Farhan, B.; Murray, A.T. Distance decay and coverage in facility location planning. Ann. Reg. Sci. 2006, 40, 279-295. [CrossRef]

43. Farhan, B.; Murray, A.T. A GIS-Based Approach for Delineating Market Areas for Park and Ride Facilities. Trans. GIS 2005, 9, 91-108. [CrossRef]

44. Farhan, B.; Murray, A.T. Siting park-and-ride facilities using a multi-objective spatial optimization model. Comput. Oper. Res. 2008, 35, 445-456. [CrossRef]

45. Orellana, D.; Guerrero, M.L. Exploring the influence of road network structure on the spatial behaviour of cyclists using crowdsourced data. Environ. Plan. B Urban Anal. City Sci. 2019, 46, 1314-1330. [CrossRef]

46. Hermida, C.; Cordero, M.; Orellana, D. Analysis of the influence of urban built environment on pedestrian flow in an intermediate-sized city in the Andes of Ecuador. Int. J. Sustain. Transp. 2019, 13, 777-787. [CrossRef]

(C) 2020 by the authors. Licensee MDPI, Basel, Switzerland. This article is an open access article distributed under the terms and conditions of the Creative Commons Attribution (CC BY) license (http://creativecommons.org/licenses/by/4.0/). 